\title{
Publisher Correction: Single-shot condensation of exciton polaritons and the hole burning effect
}

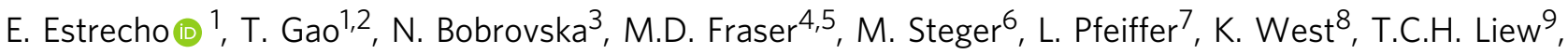 \\ M. Matuszewski (i) ${ }^{3}$, D.W. Snoke 6 , A.G. Truscott $^{10}$ \& E.A. Ostrovskaya ${ }^{1}$
}

Correction to: Nature Communications https://doi.org/10.1038/s41467-018-05349-4; published online: 9 August 2018

The original PDF version of this Article had an incorrect Published online date of 25 December 2018; it should have been 9 August 2018. This has been corrected in the PDF version of the Article. The HTML version was correct from the time of publication.

Published online: 28 August 2018

Open Access This article is licensed under a Creative Commons Attribution 4.0 International License, which permits use, sharing, adaptation, distribution and reproduction in any medium or format, as long as you give appropriate credit to the original author(s) and the source, provide a link to the Creative Commons license, and indicate if changes were made. The images or other third party material in this article are included in the article's Creative Commons license, unless indicated otherwise in a credit line to the material. If material is not included in the article's Creative Commons license and your intended use is not permitted by statutory regulation or exceeds the permitted use, you will need to obtain permission directly from the copyright holder. To view a copy of this license, visit http://creativecommons.org/licenses/by/4.0/.

(C) The Author(s) 2018

\footnotetext{
${ }^{1}$ ARC Centre of Excellence in Future Low-Energy Electronics Technologies and Nonlinear Physics Centre, Research School of Physics and Engineering, The Australian National University, Canberra, ACT 2601, Australia. ${ }^{2}$ Institute of Molecular plus, Tianjin University, 300072 Tianjin, China. ${ }^{3}$ Institute of Physics, Polish Academy of Sciences, A. Lotiników 32/46, 02-668 Warsaw, Poland. ${ }^{4}$ JST, PRESTO, 4-1-8 Honcho, Kawaguchi, Saitama 332-0012, Japan. ${ }^{5}$ Quantum Functional System Research Group, RIKEN Center for Emergent Matter Science, 2-1 Hirosawa, Wako-shi, Saitama 351-0198, Japan. ${ }^{6}$ Department of Physics and Astronomy, University of Pittsburgh, Pittsburgh, PA 15260, USA. ${ }^{7}$ Department of Electrical Engineering, Princeton University, Princeton, NJ 08544, USA. 8 Princeton Institute for the Science and Technology of Materials, Princeton University, Princeton, NJ 08544, USA. ${ }^{9}$ Division of Physics and Applied Physics, School of Physical and Mathematical Sciences, College of Science, Nanyang Technological University, Singapore 637371, Singapore. ${ }^{10}$ Laser Physics Centre, Research School of Physics and Engineering, The Australian National University, Canberra, ACT 2601, Australia. Correspondence and requests for materials should be addressed to E.A.O. (email: elena.ostrovskaya@anu.edu.au)
} 